\title{
Prospects of Using Early Neutral Evaluation in Case Management of Complex Civil Cases in Malaysia
}

\author{
Norman Zakiyy \\ Faculty of Law \\ National University of Malaysia, 43600 UKM Bangi, Selangor, Malaysia \\ zakiyy@usim.edu.my \\ Kamal Halili Hassan \\ Professor of Law, Faculty of Law \\ National University of Malaysia, 43600 UKM Bangi, Selangor, Malaysia \\ k. halili@ukm. edu.my
}

\begin{abstract}
In Malaysia, pretrial case management has been made an integral part of the litigation process since it is designed to manage cases systematically and within strict deadlines. However, dealing with the evaluative value of complex cases might not be easy, especially for the inexperienced lawyers and some judges who are not familiar with certain areas of law. This study proposes the use of early neutral evaluation for resolving complex civil cases in Malaysia during pretrial case management. Thus, this study sought to examine whether early neutral evaluation can be used effectively to identify issues at the earliest possible time to ensure early disposal or settlement of civil cases. Therefore, the objectives of this study are; first, to explore the viability of introducing an early neutral evaluation program during case management under Malaysia Rules of Court 2012; and secondly to evaluate the potential of adopting an early neutral evaluation programme in Malaysia. The finding shows that early neutral evaluation is consistent to the practice of case management under the Malaysian Rules of Court 2012. Although the Malaysia Rules of Court 2012 provides an opportunity for the adaptation of Early Neutral Evaluation, the introduction and sustainability of such programme would depend largely on a more in-depth study relating to financial resources, readiness of disputants, future goals and expectations of the Malaysian judiciary; and commitment of various stakeholders of the justice system. This study is expected to enrich present literature relating to civil procedure and also provide an overview on possible amendments to current procedural court rules particularly in Asian countries.
\end{abstract}

Keywords: Early neutral evaluation, pretrial case management, complex civil cases, Malaysia

\section{Introduction}

Modern judicial systems of these days appear to place emphasis on the importance of case management especially in civil proceedings. Primarily, it assists the court in managing the disposal of cases efficiently. Sharing similar experiences in other Commonwealth countries, case management is regarded as an integral part of civil litigation in Malaysia. Civil proceedings under the Malaysian judicial system are regulated by the Malaysia Rules of Court 2012 ("RC 2012"). The RC 2012 is largely based on common law practices. Notably, the Malaysian courts manage cases via the use of pre-trial case management ("case management") in line with its effort to uphold the interest of justice under the Order 1A of the RC 2012. It serves the purpose of narrowing down issues and enable the parties to prepare for trial (Abu Baker (2012a). In case management, pre-trial conference is held to identify issues early apart from assisting parties to prepare their case for trial. As indicated by Astor and Chinkin (1992a), the aims of the pre-trial conference are to help the parties to negotiate for a settlement apart from narrowing down the issues in dispute, thus saving judicial time. 
Seemingly, the judicial transformation of the civil courts in Malaysia (between the years of 2009-2012) had placed greater emphasis than before on case management. Joining the list of "paperless courts" in other developed jurisdictions, the Malaysian civil courts are now better known as "e-courts" and operate on an electronic court system (instead of the manual system) which comprises of the following:Case Management System (CMS); Queue Management System (QMS); and Court Recording Transcription (CRT) (Saman \& Haider, 2012; Hassan \& Mokhtar, 2011). Thus, in the Malaysian context, case management is also used as a procedural tool to reduce backlog of cases and to expedite the disposal of newly filed cases.

In order to expedite the disposal of cases, a strict deadline for the courts have been set, namely a normal civil case is expected to be resolvedwithin nine (9) months at the High Court and Sessions' Court, and within six (6) months at the Magistrates' Court. Apparently, there is clear evidence on the use of case management of the Malaysian civil courts to effectively manage "clear-cut-cases". This is evidenced by the use of an electronic court system which expedites the disposal of this category of cases. Notably, audio conferencing is used in case management (Malaysia Federal Court Circular No. 216/2010 dated 24 Aug 2010).

Accordingto the National Centre for State Courts in the United States, "complex litigation" demands rigorous judicial management. According to the Centre, complexity in a case may be determined by the following: "multiple parties, multiple attorneys, geographically dispersed plaintiffs and defendants, numerous expert witnesses, complex subject matter, complicated testimony concerning causation, procedural complexity, complex substantive law". Main obstacles to managing complex cases are difficulty in understanding and analysing the facts and laws, miscommunication between the parties, inability of counsels or parties to decide on the main issues of dispute, excessive discovery costs, multiplicity of parties and agreeable facts. It is generally known that the courts in England and Wales use multi-track system for larger and complex cases. Such a system allows complex cases to be managed closely by the courts. Be that as it may, there is little information known about whether the civil courts in Malaysia are efficient enough to manage complex cases and have them disposed within the strict or more flexible deadline. Despite the fact that audio conferencing dispenses with the need of counsels of the parties to appear at the case management date, it lacks the face-to-face interaction which allows parties to discuss openly about important issues in complex cases.

Generally, case management is geared towards early disposal of cases. Alas, the emphasis on case management has least taken into consideration the need to adopt suitable alternative dispute resolution mechanisms (ADR mechanisms) or special procedures for managing potentially difficult or protracted litigation. Against this backdrop, it is imperative to consider the importance of certain ADR mechanisms to ensure that cases are disposed within the aforementioned strict deadlines.

In the light of the above situation, it is observed that the current procedures in the RC 2012 do not address or mitigate the aforementioned problems. Evidently, many jurisdictions around the globe have promoted the use of the multi - door courthouse, which introduces a variety of ADR mechanisms. These ADR mechanisms are such as arbitration, mediation, early neutral evaluation. Mediation is used during case management in civil courts in Malaysia. By way of comparison, ENE is fairly new ADR mechanism compared to mediation. However, very little information is known about the obstacles to introducing ENE in Malaysia, taking into consideration that mediation is being promoted domestically.

Scholars generally agree that ENE is a reliable ADR process which involves the identification of core issues in a dispute prior to trial by a neutral expert (Maycock, 2001; Goss, 1995; and Goldberg, Green \& Sanders, 1985). However, ENE is least known as a form of ADR in Malaysia as well as in many parts of Asia. Although ENE is not a new dispute resolution mechanism in the United States, very little information is shared by scholars in ADR as to the suitability of ENE to address complex civil cases during case management. Lande (2008) postulates that the implementation of ENE at the early stage of the litigation track enables parties to present their respective positions before a neutral expert (i. e. the neutral evaluator). According to Zakiyy \& Hassan (2015), the process of ENE emphasises on the powerful presentation of the neutral evaluator which can assist in the exchange of information between the evaluator and the parties. The neutral evaluator will provide an evaluation of the strengths and weaknesses of each party's case. However, the viability of ENE as a potential dispute resolution mechanism is as yet to be tested or considered favourably under the RC 2012. This consideration is vital if it is found that ENE has the potential to assist the court to manage cases effectively.

Being aware of these pressing problems, the authors were motivated to study whether the goals of ENE can assist the courts in mitigating some of the said problems during case management. . Therefore, this study is significant in determining the potentials of ENE to resolve complex situations within a prescribed timeline; and the possibility of it being favourably 
considered in as a part of a "multi-door courthouse" plan in Malaysia or other Commonwealth jurisdictions. Wishfully, it may also serve as an impetus towards the carrying out of more extensive research to determine whether it is a viable ADR mechanism to be considered in both the practice and study of civil procedure, particularly in Asian countries.

Based on the above discussion, the main objective of this study is to explore the prospects of integrating early neutral evaluation in case management of complex civil cases in Malaysia. The general objectives of this study are; first, to explore the viability of introducing an ENE programme during case management under the Malaysian Rules of Court 2012; and secondly to evaluate the potential of adopting an ENE programme in Malaysia.

\section{Literature Review}

Current literature places little emphasis on ENE as a recommended ADR process. This can be contributed by the fact that mediation and arbitration are, the more preferred ADR mechanisms. Based on the above discussion, it is observed that the review of literature indicates that very little writings have associated ENE with case management, especially in the modern civil litigation system which has undergone various kinds of reforms throughout the passage of time.

According to Brazil (2002), a judicial approach to processing civil cases was significantly shown in the study conducted under the Northern District of California Early Neutral Evaluation (ENE) Programme that was headed by Joshua D. Rosenberg and H. Jay Folberg. Both scholars find that from the cases filed between mid-1988 and mid-1992, 41\% of the lawyers whose cases were automatically referred to ENE programme strongly agreed that the ENE programme made case management more efficient. However, extra caution must be taken to rely on these findings because the data was generated more than 20 years ago. In addition, many jurisdictions around the world have encountered civil litigation reforms that would have altered the way in case management is conducted. Unfortunately, over the years, hardly any studies were conducted to reinforce the findings of the study, which was done in the 80 s and $90 \mathrm{~s}$. In addition, previous studies (including those in Malaysia) do not provide answers as to whether ENE is suitable to be integrated into the case management stage involving complex cases.

Engro and Lenihan (2008a) describe ENE as an evaluative process which is not intended for settlement alone, but is capable of designing better ways to manage cases more efficiently. They based their assumption on the argument that the purpose of mediation is not similar to ENE. This is because the mediation's purpose is to encourage disputing parties to reach a settlement, but ENE's purpose is not limited to settlement alone, but extends to providing them with a better understanding of their dispute. Wissler (2004) in her summary of empirical research found that the introduction of ENE reduces cases from being heard at trial.

Similarly, more recent studies have not emphasized the connection between ENE and case management, but on the subject of effectiveness. In 2010, for example, Carolyn Hay, Katharine McKenna and Trevor Buck (2010) examined the cost effectiveness of ENE in the social security and child support tribunal. The aim was to investigate whether it produces swifter, more proportionate resolution of cases. Apart from that, the research also aimed to establish appellant's satisfaction with the process and the impact on and views of stakeholders.

Based on the above, none of the studies have dealt with the relationship between ENE and case management in depth. Under the foregoing, this studyhopes to fill the existing gaps in the literature and also to increase the literature in the areas of ENE and case management in Malaysia.

\section{Methodology}

Studies in procedural law generally involve analysis of statutes, reported case laws, court procedural rules and court practice directions. This study depended largely on secondary data. The major sources of data include journal articles, reported cases, procedural rules and relevant information retrieved from the internet. The methods employed in this study were descriptive aimed at fact finding and positive analytical criticisms which were aimed at improving the existing manner of managing complex cases by using ENE in case management. In carrying out this task, the relevant procedural provisions in the RC 2012 and relevant documents were analysed to find out whether it is plausible for ENE to be used during the process of case management. 


\section{Findings and Discussion}

This study attempted to gain an understanding of the prospects of ENE in civil procedure in Malaysia by looking atthe viability of introducing ENE during case management under the Malaysia RC 2012; and secondly to evaluate the potential of adopting an ENE programme in Malaysia.

\section{1 Findings}

4. 1. 1 The study indicates that ENE is an effective tool in case management of complex cases. It is imperative to note the following findings:
(a) ENE's goals are quite similar to those stipulated in case management under the RC 2012.
(b) A competent neutral evaluator is capable of assisting the court in managing trial of complex cases by identifying issues at the case management stage.
(c) The face-to-face interaction between the neutral evaluator on the one part and the parties and lawyers on the other part allows complex issues to be analysed in terms of merits, comprehended, resolved or even planned for trial.
(d) Both ENE and case management under the RC 2012 are held early upon the commencement of legal action in the court thus allowing ample time for the court to manage and the parties to prepare the case more efficiently and in a systematic manner.
(e) There are potentials of adopting ENE in Malaysia but subject to certain constraints such as insufficient financial funds, understanding among the legal fraternity, cost effective and appropriate training.

\section{2 Discussion}

4. 2. 1. The discussion below shows how the advantages of introducing ENE in case management:

\section{(a) ENE's goals are quite similar to those stipulated in case management under the RC 2012.}

Practically, the court requires cooperation from attorneys representing the parties to ensure that case management of their case is managed effectively. In Malaysia, attorneys handling civil cases are commonly referred as "solicitors", thus the term "solicitors" would be referred herein from this point onwards). Typically, the goals of the ENE programme are namely, (1) to enhance communication between the parties; (2) to provide an evaluation of the merits of the case; (3) to provide a "reality check" for both clients and solicitors; (4) to identify and clarify central issues in dispute; and (5) to assist in settlement discussions. By way of comparison, it is imperative to highlight that many major goals of ENE are similar to the objectives of holding the pre-trial conference, especially in terms of enhancing communication among the parties, identifying facts and issues, assessing strengths and weaknesses of each party, and improved court administration. Astor and Chinkin (1992), succinctly pointed out the objectives of the pre-trial conference are as follows:

i) Guiding parties to communicate with each other;

ii) Scrutinizing facts and separating issues;

iii) Assessing strengths and weaknesses of a case;

iv) Assessing possible risks and quantum;

v) Decreasing trauma of the adversarial method;

vi) Educating parties in court procedures;

vii) Ensuring plaintiffs are paid earlier;

viii) Ensuring costs as low as conceivable;

ix) Efficient court management; and

$x$ ) Trying to ensure that only obstinate cases proceed to trial. 
Thus, the sharing of a number of similar goals between ENE and pre-trial conference draws the inference that ENE can be integrated into case management in order to enhance greater communication, participation among the parties and in the disposal of cases. This is consistent with the view of Abu Baker (2012b) who stressed on determining the issues for trial during case management. Thus, the inference that can be drawn from this study is that ENE is appropriate to be applied under case management under the RC 2012 to reduce the complexity of a case.

\section{(b) The neutral evaluator is a skilful manager who can assist the judge in managing complex cases or situations}

Scholars generally agree that it is important for a manager to manage complex situation in a competent and efficient manner. For example, competency is said to include a "combination of knowledge, skills, behaviour and attitudes" (Hellriegel et. al. , 2000). These profound competency values should be possessed by a judge or judicial officer who manages the case management of a case. Thus, important matters must be clarified with the parties. The list of important matters differs from jurisdiction to jurisdiction. However, it can be generally accepted that these important matters include the particulars of the claim and defence, principal issues that need to be determined at trial, the use of experts, number of witnesses, agreed and non-agreed facts. It is also generally perceived that competency is a major factor of any organizational success (Whetton \& Cameron, 2002; Lewis et al. , 2004; and Schermerhorn Jr, 2002). This principle is equally applicable in court management. Therefore, if the judge is incompetent or less competent in resolving complex legal issues at the case management stage, the engagement of acompetent party in certain areas of law (in this regard, the neutral evaluator) might assist in managing complexity in civil proceedings. It can be inferred that the views of a highly respected neutral may also assist in persuading the parties to negotiate. This is because the neutral evaluator is usually appointed amongst individuals who are former retired judges or senior lawyers. Thus, he can assist the parties in the event a deadlock takes place in complex cases. Moreover, Engro and Lenihan (2008b) aver that ENE offers better ways to manage cases efficiently because it does not only emphasise on settlement plan but greater understanding of the case.

\section{(c) ENE ascertains complex issues at the early phase of a case}

Under the RC 2012, the civil courts will normally fix the pre-trial case management early. For example, it is fixed approximately around two (2) weeks upon the commencement of a court action. Similarly, ENE is held early in the litigation process. Zakiyy \& Hassan (2014) and Trendle (2004) postulate that ENE should be introduced into the litigation process at an early stage and even at the pre-litigation stage or before the referral to any ADR mechanism.

In Malaysia, the majority of the e-courts are depending on effective ways of managing cases. These effective ways are referred to the e-court system. Under the electronic court system, newly filed cases are now placed under case management system (CMS) and its sub-modules (namely the e-filing and e-registration) to improve efficiency. At the first pre-trial case management, many issues are not determined. In such situation, the court's guidance on future directions is needed.

In the early phase of a case, the neutral evaluator may assist the court in managing the future directions of the parties especially to identify complex issues. The evaluator emphasizes on connectivity with her audience during the ENE session. This is to ensure that her audience receives her message clearly (Zakiyy \& Hassan, 2015). Dayton (1991) mentioned that the neutral evaluator is trained to provide "an early, frank and thoughtful assessment" of the "relative strengths and weaknesses" of each party. In addition, the holding of ENE at the pre-trial stage is in consistent with the view ofMacfarlanes, LLP (2014) who explained that in complex cases, ENE provides better discussion on settlement at the early phase of a case even before the exchange of court documents. Therefore, it is observed that the neutral evaluator may assist the court to achieve some, if not all of the objectives of the pre-trial conference as specified above.

\section{(d) ENE assists the court and the parties in the clarification and narrowing down of issues}

Under Order 34, rule 3 of the RC 2012, the court is empowered to fix the date and time for case management. The parties must comply with such court order, failing which the action may be dismissed without hearing on the merits. Under Order 34 , rule 6 of the RC 2012, the Court is also empowered to dismiss the action or proceedings or strike out the defence or 
counterclaim or enter judgment or make such other order as deemed fit if any party fails to attend to it (Order 34 , rule 6 of the RC 2012). At the pre-trial case management hearing, the parties can either attend the session personally or, in addition to their solicitors (Order 34, rule 4 of the RC 2012).

There is a plethora of legal authorities which states that case management orders are to be obeyed and not to be broken, without proper reason (s). For example, in the case of Nur Ibrahim Masilamani \& Anor v. Joseph Lopez (per judgment of Yeoh Wee Siam J) [2013] 4 CLJ 1202 [HC], the High Court inter alia held that all court orders given in pre-trial case management must be complied by the parties according to a strict deadline for the purpose of expediting the trial. Thus, non-compliance by a party with court's direction in case management is detrimental to his own interest. For example, Order 34 of the RC 2012 stipulates the need of the party to comply to the court's order in case management, failing which the action may be dismissed. The importance of this particular order is stressed by the courts by issuing parties with a copy of instruction pertaining to the responsibilities of the parties in case management. This is exemplified in the recent Kuala Lumpur High Court case of Perbadanan Pengurusan Palm Spring Damansara v. Muafakat Kekal Sdn Bhd \& 2 Ors. [2014] 1 LNS 1633, whereby the parties were issued a copy of "Enclosure A" containing instructions to comply with the directions of the court during case management and the consequences of non-compliance.

Accordingly, Order 34 of the RC 2012 also specifies that at the pre-trial case management stage, the judge may inter alia do the following:

a) Direct parties to refer the matter in dispute to mediation in accordance with any practice directions for the time being issued (0.34, rule 2 (2) (a) of the RC 2012);

b) Fix the period within which the plaintiff is to file the bundle of pleadings (Order 34, rule 2 (2) (b) of the RC 2012);

c) Fix the period within which the parties are to file the bundle of documents including documents mentioned in the witness statement of a witness Order 34, rule 2 (c) of the RC 2012);

d) Direct the parties to identify the contents of the bundle of documents and bundle up the documents into agreed bundle of documents which shall be filed by the plaintiff ( Order 34, rule 2 (d) of the RC 2012);

e) Direct the parties to identify certain documents where no agreement can be reached $(0.34$, rule 2 (e) of the $R C$ 2012);

f) Direct the filing of statement of agreed facts (Order 34, rule 2 (j) of the RC 2012); and

g) Direct the filing of statement of issues to be tried (Order 34, rule 2 (k) of the RC 2012).

Order 34 of the RC 2012 stipulates that the court can direct the parties to mediation. Based on the expertise of the neutral evaluator, it can be inferred that the neutral evaluator can similarly assist the court to clarify certain complex issues that have been raised by the parties or their solicitors as shown in their respective pleadings. Each solicitor may propose a number of issues which may or may not be accepted by the other side's solicitor. Thus, the neutral evaluator uses his expertise in the substantive law relating to the dispute by determining and narrowing down the issues. This saves the court, judicial time in determining the issues to be tried.

\section{(e) ENE assists the parties in comprehending the reality of each other position}

Similarly, under the RC 2012, the parties or their solicitors are required to comply with the court orders, especially in terms of preparing the bundle of pleadings (Order 34, rule 2 (2) (b) of the RC 2012) and identifying certain documents where no agreement can be reached (Order 34, rule 2 (e) of the RC 2012). During case management, it is assumed that the solicitors for each party would have examined thoroughly the statement of claim, defence and other related pleadings (if any), case law governing a subject matter. However, it is common to find that they would still be required to identify documents which are mutually agreed or otherwise. In the recent High Court civil appeal case of Malayan Banking Bhd v. Sunlight Seafood Sdn Bhd [2015] 4 CLJ 272], SM Komathy JC, in her judgment, inter alia cautioned that at the stage of setting down the action for trial, it is the responsibility of the plaintiff to bring to the court the relevant evidence in support of his case). In a highly complex case, an expert in a specific area of substantive law may help the parties to check on the prospects of their case and to simplify evidence by making it comprehensible to the parties. A sound advice from the neutral evaluator might avoid the parties from being involved in protracted litigation and incur escalating costs. Thus, according to Stradley, Ronon, Stevens \& Young, LLP (2007), the neutral evaluator will usually allow each party to present her claims and defence during the ENE session. This opportunity enable the parties to achieve some of the major goals of ENE, namely to assess the strength and weaknesses of each other position. This opportunity essentially allows them to decide on whether it is worthwhile for their dispute to be heard in a full trial or plan for possible settlement. 
It is a totally a different experience for the parties (or their solicitors) to discuss about their case before a judicial officer in pre-trial conferences with the usual formality compared to a neutral evaluator in an ENE session. The involvement of the neutral evaluator in a different forum (namely the ENE session) would allow her to get the best cooperation from the parties and their solicitors to communicate effectively with each other freely. This in turn enables the neutral evaluator to render her advice to them on the merits of their case.

\section{(f) ENE assists the parties in settlement discussion and case planning}

Accordingly, at the case management stage, the judge may direct parties to refer the matter in dispute to mediation in accordance with any practice directions for the time being issued (Order 34, rule 2 (2) (a) of the RC 2012). Mediation often results in settlement discussion. However, ENE has the potential of extending it to case planning, especially if mediation fails to convince the parties to reach settlement. Communication is clearly emphasized in the ENE session. This fact is clearly stated by Brazil (2007) who opines that the neutral evaluator would ensure that each party is made aware of "every bit of the arguments and evidence brought forth by each other". With such full and frank disclosure, there is plenty of room for the parties to discuss about possible settlement at the pre-trial case management stage. As indicated by Engro and Lenihan (2008), the neutral evaluator may even conduct settlement discussion if the parties agree to do so. In the absence of such agreement, the neutral evaluator will present his verbal evaluation of the case before her audience (namely, the parties, their solicitors and witnesses). This evaluation will essentially include the strengths and weaknesses of each party's case. Since the neutral evaluator can also assist the parties in case planning, the introduction of ENE during case management may assist the court to manage the progress of the case more efficiently.

\section{Potential of Introducing ENE Programme in Malaysia}

The court procedures of the Malaysian judicial system are largely based on common law practices. As a Commonwealth country, there is inclination by the Malaysian Judiciary to refer to the English Civil Procedure Rules 1998 (see Rule 1. 4 Civil Procedure Rules 1998) which include active case management by the court by identifying the issues at an early stage, controlling case progress and encouraging parties to use appropriate ADR mechanisms. In the Northern District of California, for example, the court sponsors four (4) major ADR mechanisms: Arbitration, early neutral evaluation, mediation and settlement conferences. However, as emphasised by Moore (2000), for a new mechanism to be introduced, it often has to undergo a rigorous test from its users by being recognised as widely supported. It is clear that for every new programme to be successful, the parties are presumptively required to participate in any of the available court ADR programme.

Evaluators under the court ENE programme are generally appointed by the court among those who are retired judges or senior lawyers. It is observed in Malaysia that many senior lawyers (and some former judges) are practicing arbitrators or mediators. In Malaysia, there are indications that judicial officers with specialized experience in substantive areas of the law are engaged in the resolution of disputes. This is evidenced by the effort by the Malaysian judiciary in establishing numerous specialised courts aimed to resolve disputes expeditiously and to reduce the occurrence of case backlog (Arifin Zakaria, 2012). Some of these specialised courts are namely the New Commercial Court (NCC), the Corruption Court, the Admiralty Court, the Environmental Court and the Muamalat Court (Islamic Banking Court). Notwithstanding this fact, the assistance of highly qualified lawyers with similar experience and abilities as that of the judges is crucial if the parties opt to resolve their disputes by way of ADR instead of the litigation process. In fact, under the RC 2012, there is a provision pertaining to the appointment of joint expert or assessor (Order 33, rule 1 of the RC 2012). However, the Malaysian courts hardly utilise thisprovision during the case management stage. This provision is vital in determining the strengths and weaknesses of a pending case.

Apart from mediation, arbitration has also gained recognition for being known as an efficient dispute resolution mechanism in dealing with complex technical issues. However, it is noted that not all construction disputes involve technical issues, but more on the interpretation of a specific clause in the construction contract. According to Onn (2003), there is a clear distinction between a technically qualified arbitrator and one who is an expert in substantive law. Onn (2003) opines that: "that a technically qualified arbitrator may not have a real advantage: there is a distinction between an arbitrator using his 
technical knowledge and expertise to understand and evaluate the evidence before him and to provide or fill the gap of the evidence himself".

There are sufficient number of senior lawyers who possess skills and experiences in certain substantive law areas such as insurance, intellectual property laws and Islamic banking. Based on the general statistics issued by the Malaysian Bar, there is a steady increase in the number of lawyers throughout the years of 2011 and 2014, notably, in 2011 (13672), 2012 (14517), 2013 (15331), 2014 (16300). There is only a slight decrease in year 2015 (15896 lawyers). In Malaysia, lawyers who have been in practice for 7 years or more are considered as senior lawyers. Apparently, there are currently more than 8000 senior lawyers who are more than 12 years of experience (Malaysian Bar, 2015). This figure, which stands as of 9 March 2015 is based on the breakdown by number of years of experience which is revealed by the Malaysian Bar. In 2013, the number of senior lawyers with 7 to 12 years of experience is 2352. In 2014, there are 2353 lawyers, whereas in 2015, there are 2236 lawyers. In 2014, the number of senior lawyers with more than 12 years of experience is 8014 . In 2014, there were 7316 lawyers and in 2015, the figure stands at 8053 . Based on these statistics, it can be safely assumed that the legal profession in Malaysia has a number of senior members who has vast years of experience in various areas of substantive laws. Many of them have gained sufficient experience in handling a number of complex high profile civil litigation. Apart from handling litigation, many are practicing mediators and arbitrators. Nonetheless, their expertise is least known to have been put into worthy use. Nevertheless, none has the opportunity to serve as early neutral evaluators. Under such foregoing, it remains inconclusive as to whether ENE might be easily accepted as a reliable ADR mechanism in Malaysia, especially when ENE is as yet to be tested by the Malaysia civil courts. In light of the foregoing, it is suggested that the introduction of ENE needs to be supported by external organisations. Apart from the Kuala Lumpur Regional Centre for Arbitration (KLRCA) which promotes itself as an international centre for resolution of disputes via ADR, there is as yet any centre which emphasises in conducting in-depth research on the use of ADR in Malaysia. Thus, such a centre could be established by local institutions of higher learning. These local institutions can gain better understanding about the workability of certain ADR mechanisms by studying the theoretical strength of certain ADR mechanisms. The study may also be extended to the practical side of certain ADR mechanisms by referring to the courts or private ADR providers in other countries which have already been offering numerous types of ADR mechanisms (including ENE) for a considerable number of years.

It is generally assumed that courts around the world encourage parties to consider settlement instead of litigating their disputes. In Malaysia, it is axiomatic to note that at the case management stage, settlement is the main goal of the Court (Order 34, rule 2 of the RC 2012). To achieve settlement, the parties are encouraged to use mediation, especially in light of the existing practice direction on mediation which was issued by the Office of the Chief Registrar of the Federal Court of Malaysia in 2010 (Practice Direction No. 5 of 2010). It is trite law that practice directions are not rules of court (re Langton (1960) 1 WLR). In Jayasankaran v. PP (1983) 1 MLJ 379, the Federal Court of Malaysia held that practice directions are meant for administrative purposes only. Nevertheless, the court may still order parties to adhere to certain practice directions to reduce backlog of cases. There is a plethora of scholarly views on the drawbacks of mediation. These drawbacks are due to the following reasons: (i) the mandatory nature of court-connected mediation which hampers the parties' intention to reach a settlement (Zakiyy, 2010; Hedeen \& Coy, 2000); (ii) the parties mediate without knowing about its process or how to participate in it (Hedeen, 2012); and (iii) and it is a high risk process if the mediator lacks the skills or behaves unethically (Sheppard, et. al. , 1993). In addition, the World Bank reported that mediated cases in Malaysia are comparatively low compared to other countries; and is practically introduced after the case management (World Bank Report, 2011). Thus, under the prevailing circumstances, it is difficult at this point of time to predict the reception of ENE in light of the current inclination of the court and solicitors to refer disputes to mediation.

Another obstacle, possibly faced in introducing ENE is costs. A systematic training for evaluators will require a high budget. Any proposal to recommend the kind of training should take into consideration of entry level, intermediate level or specialized level affecting the more complex cases. In this regard, it is recommended that both substantive law experts and professional training organizers should work together to figure out the best form of training. 


\section{Implications of the Study}

The insights derived from this study have vital implications for the manner of managing case management as well as the preparations of effective dispensation of justice in complex cases. Having the assistance from a neutral evaluator with solid background of a subject matter will definitely be of great assistance to the solicitors to develop rational advice in order to cater to the needs of their respective clients as to the next logical course of action in the litigation process, namely either to look forward to a settlement plan or proceed to trial. The traditional approach to case management has been to treat all cases as the same domain. This means that during case management, the court only manages a case according to its understanding of the issues, facts and laws of a case. Therefore, the assumption of such practice is that with certain effort to narrow down the issues and relevant facts of a particular case, the court and solicitors representing the respective parties will be able to comprehend a case accordingly. However, it is evident that in dealing with a complex case, this is not sufficient to prepare the parties for their preparation for trial or even possible settlement discussion. The analysis has shown that it is obvious that complex cases must be treated indifferently for non-complex cases for the sake of efficiency and in the name of justice.

\section{Conclusion}

It is assumed that early and efficient disposal of cases is always expected from a world class judicial system. In this context, ENE should not be left out from the umbrella of reliable ADR mechanisms. Certainly, we have to acknowledge that there are advantages in exploring and embracing ADR mechanisms which are consistent with the need of the court to dispose cases efficiently. In this context, It is worthy to consider ENE in managing complex cases, especially at the pre-trial stage. It only needs more promotion and recognition, especially by countries in Asia. The study has shown that ENE is an effective ADR mechanism which is capable of identifying complex issues that are not easily identified by the courts, the parties or their solicitors. It is the answer to many complex situations in civil proceedings such as complex evidence and issues. In summation, a clear understanding of its goals and mights might enable it to be easily accepted by the courts, the legal fraternity and the public at large.

\section{Limitations of the Study}

This study has encountered the usual limitations of time and funds commonly faced by a non-funded study. Thus, this study can only be considered as a preliminary and a modest contribution to elicit further enquiry on the might of ENE in case management.

\section{Recommendations for Future Study}

As hereinbefore mentioned, active case management is an integral part of civil litigation in Malaysia and even in most Commonwealth countries. In this regard, the use of ADR is an option to increase efficiency in the management of cases during the case management stage. It is recommended that the courts and the Malaysian Bar must initiate awareness among the parties about the credibility and effectiveness of ENE in solving complex disputes. In any court sponsored ENE programme, the parties must be given the liberty to withdraw from the ENE session if the neutrality of the neutral evaluator is questionable. This is vital for the parties to rely on the advice of the neutral evaluator without the slightest doubt about his neutrality. It is suggested that a more in-depth study be conducted on the suitability of ENE to resolve a myriads of disputes and its effectiveness when combined with other ADR mechanism (s).

\section{References}

[1] Abu Baker, H. S. B. (2012), Janab's Key to Civil Procedure - COMBINED RULES (The Rules of Court 2012 Annexed), (5th. Ed. ), Janab (M) Sdn. Bhd. , Malaysia. 
[2] Astor, H. , \& Chinkin, C. M. , (2002), Dispute Resolution in Australia. (2nd Edn. ). Butterworths (Canada) Limited.

[3] Brazil, W. D. (2007). Early Neutral Evaluation or Mediation - When Might ENE Delivery More Value, Berkeley Law Scholarship Repository, http://scholarship. law. berBerkeley. edu/cgi/viewcontent. cgi?article=1164\&contexts=facpubs (December 16, 2013).

[4] Brazil, W. D. (2002). Court ADR 25 Years After Pound: Have We Found a Better Way?. Ohio State Journal on Dispute Resolution [Vol. 18:1 2002].

[5] Dayton, K. , The Myth of Alternative Dispute Resolution in the Federal Courts, 76 lowa L. Rev. 889, July 1991.

[6] Engro, K. , and Lenihan, L. P. , Understanding Early Neutral Evaluation in the Western District of Pennsylvania, 10 Lawyers J. 3, 2008.

[7] Goss J. (1995). An Introduction to Alternative Dispute Resolution, Alberta Law Review, [Vol. XXXIV, N 1 , 1995).

[8] Goldberg, S. B. , Green E. D. \& Sanders F. E. A. (1985). Dispute Resolution. Toronto: Little, Brown and Company.

[9] Hassan K. H. \& Mokhtar M. F. , The E-court System in Malaysia, A paper presented at the 2011 2nd International Conference on Education and Management Technology, http://www. ipedr. com/vol13/46T10012. pdf, IPEDR vol. 13 (2011) @ (2011) IACSIT Press, Singapore, (accessedNovember 1, 2014).

[10] Hassan, K. H. , and Mokhtar M. F. , The Court System in Malaysia, The $20112^{\text {nd }}$ International Conference on Education and Management Technology Proceedings, Singapore, 2011, p 240. IPEDR vol. 13 (2011).

[11] Hay, C, McKenna, K and Buck, T (2010). Evaluation of early neutral evaluation alternative dispute resolution in the social security and child support tribunal, Ministry of Justice Research Series 2/10, London: Ministry of Justice. Accessible at http://www. justice. gov. uk/publications/early-neutral-evaluation-sscs. htm

[12] Hellriegel D. , Jackson, S. E. , \& Slocum, Jr. , J. W. (2002). Management: A competency-based approach, South-western. (9th. Edn. ). ThomasLearning.

[13] Hedeen, T \& Coy, P. G. (2000). Community Mediation and the Court System: The Ties That Bind. Mediation Quarterly, 17 (4) (2000): 351-67.

[14] Hedeen, T. (2012). Remodelling the Multi-Door Courthouse to "Fit the Forum to the Folks". How Screening and Preparation will Enhance ADR. ADR, 95 Marq. L. Rev. 941 (2012). [Online]. Available: http://scholarship. law. marquette. edu/cgi/viewcontent. cgi?article=5118\&context=mulr (retrieved: June 5, 2015).

[15] Lande, L. , The movement Toward Early Case Handling in Courts and Private Dispute Resolution. Ohio State Journal on Dispute Resolution, 24 Ohio St. J. on Disp. Resol. 81, 2008.

[16] Maycock, E. M. , Mediator Focus: Early Neutral Evaluation. Utah Bar Journal, 36 (November, 2001, 14 Utah Bar J. 36, 2001.

[17] Macfarlanes, LLP. (2007). Litigation in-brief. [Online]Available: http://www. macfarlanes. com/media/320507/early\%20neutral\%20evaluation. pdf (February 10, 2014).

[18] Moore, M. , (2002). Managing for Value: Organisational Strategy in for Profit, Non Profit Governmental Organisation. Non Profit and Voluntary Sector Quarterly 29:183-208.

[19] Malaysia Federal Court Circular No. 216/2010 dated 24 Aug 2010.

[20] National Centre for State Courts in the United States, "complex litigation" demands rigorous judicial management. Available: http://www. ncsc. org/Topics/Civil/Complex-Litigation/Resource-Guide. aspx (February 3, 2014). 
[21] Oon C. K. . , Arbitration in Construction Disputes

[22] A Procedural and Legal Overview, Available: http://www. ckoon-law. com/Paper/ARBITRATION\%20IN\%20CONSTRUCTION\%20DISPUTES. pdf (June 6, 2015).

[23] Saman W. S. W. \& Haider, A. Electronic Court Records Management: A Case Study, Journal of e-Government Studies and Best Practices. Available:http://www. ibimapublishing. com/journals/JEGSBP/jegsbp. html, Vol. 2012 (2012), Article ID 925115, DOI: 10. 5171/2012. 925115 (November 1, 2014).

[24] Schermerhorn J. R. (2002). Management (7th. Ed. ). John Wiley \& Sons, Inc. Canada Ltd.

[25] Sheppard et al. , (1979). National Evaluation of the Neighbourhood Justice Centre Field Test-Interim Report. Washington DC: Department of Justice.

[26] Stradley, Ronon Stevens \& Young, LLP, A Snapshot of Early Neutral Evaluation, The ADR Advisor. http://www. stradley. com/library/files/adradvisorspring_07. pdf (December 16, 2013)

[27] Trendle, Judicial Case Management: Rellocating Responsibilities, Paper submitted at the $18^{\text {th }}$ International Conference of the International Society for the Reform of Criminal Law, Montreal, 8-12 August 2004 as cited in E. Bell, Judicial Case Management [2009:2] Judicial Studies Institute Journal.

[28] The official website of the Malaysian Bar,

[29] http://www. malaysianbar. org. my/general_notices/bc_general_statistics_2013. html [Online] (June 1, 2015).

[30] Wissler, R. , The Effectiveness of Court-Connected Dispute Resolution in Civil Cases, 22 Conflict Resol. Q. 55 (2004) (summarizing empirical research on court-connected mediation and early neutral evaluation).

[31] Whetton, D. A. \& Cameron, K. S. (2002). Developing Management skills, (5th. Ed. ), Prentice Hall.

[32] Lewis, P. S. , Goodman, S. H. \& Fanth, P. M. (2004) Management Challenges for Tomorrow's leaders, (4th. Ed), Thomson South-western.

[33] World Bank (2011), Court Backlog and Delay Reduction Programme: Malaysia Court Backlog and Reduction Program: A Progress Report, published by the World Bank in August 2011. [Online]. Available: http://www. kehakiman. gov. my/?q=download/file/fid/1489 (September 30, 2013).

[34] Zakaria, A. , Improving Court Efficiency: Better Methods For Case Management And Procedural Efficiency (with emphasis on recent initiatives in the reduction of court backlogs and enhanced efficiency). [Online]. Available: http://www. kehakiman. gov. my/sites/default/files/document3/Penerbitan\%20Kehakiman/Malaysia\%20Court\%20Backlog\%20and\%20Delay $\% 20$ Reduction $\% 20$ Program_power\%20point $\% 20$ presentation $\% 20$ by $\% 20$ The $\% 20 \mathrm{Hon}$. \%20Tun\%20Zaki\%20Tun\%20Azmi. pdf (June 5, 2015).

[35] Zakiyy, N. , \& Hassan, K. H. , Integrating Early Neutral Evaluation into Mediation of Complex Civil Cases in Malaysia, Journal of Politics and Law; Vol. 7 No. 4; 2014.

[36] Zakiyy, N. \& Hassan, K. H. (2015), The Use of Powerful Presentation in the Introductory Phase of Early Neutral Evaluation Session, International Journal of Liberal Arts and Social Science, Vol. 3 No. 4April, 2015.

[37] Zakiyy, N. , 2010, Court Annexed Mediation in Resolving Disputes Relating to Family in Malaysia, Malaysian Journal of Syariah and Law, Vol. 2/2010: 144. 